\title{
Combination effect of melatonin and dexamethasone on liver ischemia/reperfusion injury
}

\author{
Taghizadieh $\mathrm{M}^{1}$, Hajipour $\mathrm{B}^{2}$, Ahmadi Asl N³ , Khodadadi $\mathrm{A}^{4}$, Somi $\mathrm{MH}^{5}$, Banei $\mathrm{M}^{2}$ \\ Department of Surgery, Urmia University of Medical Sciences, Urmia, Iran. Hajipourb@yahoo.com
}

\begin{abstract}
OBJECTIVE: Liver failure following ischemia-reperfusion $(\mathrm{I} / \mathrm{R})$ injury is a major concern in liver surgery. The purpose of this study was to evaluate combination pretreatment with melatonin (MEL) and dexamethasone (DEX) on liver I/R model. Male Wistar rats $(n=60)$ were assigned to 5 groups of 12 animals each: (1) Sham: laparotomy without I/R; (2) I/R: hepatic I/R; (3) I/R+MEL: hepatic I/R+melatonin injected intraperitoneally (20 mg/kg); (4) I/ R+DEX: hepatic I/R+ dexamethasone injected intravenously $(10 \mathrm{mg} / \mathrm{kg}) ;(5) \mathrm{l} / \mathrm{R}+\mathrm{MEL}+\mathrm{DEX}$ : hepatic I/R+ melatonin injected intraperitoneally+dexamethasone injected intravenously. The liver was subjected to ischemia by clamping the portal triad for 30 minutes and then reperfused for 6 hours after ischemia by removing the clamps. RESULTS: The levels of glutathione peroxidase (GPX) and superoxide dismutase (SOD) decreased after hepatic $\mathrm{I} / \mathrm{R}$ in all groups. Levels of GPX and SOD were higher in I/R+MEL+DEX group compared to I/R, I/R+MEL and I/ $R+D E X$ groups and they were significantly higher in $I / R+M E L$ group compared to $I / R$ and $I / R+D E X$ groups $(p<$ 0.05 ). Levels of ALT, AST, TNF-a, hepatic tissue malondialdehyde (MDA), liver injury index, and apoptotic index increased after hepatic I/R. Levels of ALT, AST, tissue MDA, tissue injury index and apoptotic index were lower in $1 / R+M E L+D E X$ group compared to those in $I / R, I / R+M E L$ and $I / R+D E X$ groups, and in $I / R+M E L$ they were significantly lower than in I/R+DEX group $(p<0.05)$. TNF- $\alpha$ level was lower in $I / R+M E L+D E X$ group compared to other groups and it was significantly lower in I/R+DEX group than in $I / R+M E L$ and $I / R$ groups $(p<0.05)$. CONCLUSION: Combination therapy with melatonin and dexamethasone had better results in decreasing the liver injury compared to when each of them was administered alone (Tab. 3, Ref. 58). Text in PDF www.elis.sk. KEY WORDS: liver, ischemia/reperfusion, melatonin, dexamethasone, rat.
\end{abstract}

\section{Introduction}

Hepatic ischemia-reperfusion ( $/ / \mathrm{R})$ injury is a serious complication. It is an unavoidable problem and may occur under different clinical conditions. These include the complete temporary occlusion of the supplying blood vessels during liver surgery, especially when dealing with extensive hepatic trauma or resection of large intrahepatic lesions such as cysts or tumors (1). The use of extracorporeal circulation in cardiac or vascular surgery is associated with low-flow I/R of the liver. Moreover, hepatic low flow $\mathrm{I} / \mathrm{R}$ often occurs during hemorrhagic and septic shocks, cardiac infarction and heart failure states, and is followed by improvement in blood perfusion. Besides these, variety types of warm I/R and cold I/R occurring during liver transplantation play an important role in inducing liver I/R injury (2).

${ }^{1}$ Department of Pathology, Tabriz Branch, Islamic Azad University, Tabriz, Iran, ${ }^{2}$ Department of Surgery, Urmia University of Medical Sciences, Urmia, Iran, ${ }^{3}$ Department of Physiology, Tabriz University of Medical Sciences, Tabriz, Iran, ${ }^{4}$ Veterinary Faculty, Tabriz Branch, Islamic Azad University, Tabriz, Iran, and ${ }^{5}$ Liver and Gastroenterology Research Center, Tabriz University of Medical Sciences, Tabriz, Iran

Address for correspondence: B. Hajipour, MD, Department of Surgery, Urmia University of Medical Sciences, Urmia, Iran.

Acknowledgments: This work was supported by a grant from Islamic Azad University, Tabriz Branch.
Hepatic I/R represents a complex series of events that result in cellular and tissue damage. Deprivation of oxygen in the liver during ischemia induces severe lesions but much more important ones originate during reperfusion when oxygen entry to the organ is restored (3). An excessive inflammatory response is clearly recognized as a key mechanism of injury during reperfusion (4). Activation of Kupffer cells results in the production and release of proinflammatory cytokines, including tumor necrosis factor alpha (TNF- $\alpha$ ) and interleukin $1 \mathrm{~b}$ (IL-1b) (5). These cytokines affect surrounding hepatocytes, including the chemokine production. Hepatic production of TNF- $\alpha$ is increased shortly after reperfusion and has powerful effects not only on the local hepatic environment, but also on remote organ function, most notably in lung (6), which is the main source of vascular reactive oxygen formation during the initial reperfusion period (7). Interestingly, this effect is only observed after no-flow ischemia (pringle, transplantation) but not after hemorrhagic shock, i.e. low-flow ischemia (8). In addition to Kupffer cell-induced oxidant stress, with increasing length of the ischemic episode, intracellular generation of reactive oxygen by xanthine oxidase, and in particular the mitochondria may also contribute to liver dysfunction and cell injury during reperfusion (9).

Variety of drugs have been used for decreasing hepatic I/R injury, but regarding underlying mechanisms in initiating the injury, researches for finding better and more effective protocols are under consideration. Because free oxygen radicals are involved 
in ischemia/reperfusion injury, a group of anti-oxidants has been targeted as potential useful protective agents against liver injury after hepatic ischemia reperfusion (10). Melatonin (N-acetyl-5-methoxytryptamine, $\mathrm{C}_{13} \mathrm{H}_{16} \mathrm{~N}_{2} \mathrm{O}_{2}$ ) is an effective free radical scavenger and it is produced from L-tryptophan and secreted from some of mammalian organs like the pineal gland, retina, and gastrointestinal tract (11). Melatonin received considerable attention because of its anti-oxidative property. This substance can directly neutralize free radicals and it has indirect anti-oxidative effects as it stimulates the expression and activity of anti-oxidative enzymes such as glutathione peroxidase (12) and super oxide dismutase (13). Being a highly lipophilic substance, melatonin easily penetrates inside the cell to stabilize lipid membranes from peroxidation and to protect the intracellular structures from damage (14). Previous studies have shown that melatonin plays a role in protection of antioxidative enzymes from oxidative damage, and it has been proven highly effective in lowering molecular damage under conditions of elevated oxidative stress and free radical-mediated apoptosis (15). It is also indicated that melatonin can decrease I/R-induced injury in different organs (16). Corticosteroids are important antiinflammatory agents for various inflammatory processes including asthma, trauma, surgical procedures, and many other inflammatory and immune diseases. The predominant effect of corticosteroids is to switch off multiple inflammatory genes (encoding cytokines, chemokines, adhesion molecules, inflammatory enzymes, receptors, and proteins) that have been activated during the inflammatory process. They have additional effects on the synthesis of anti-inflammatory proteins, and also post-genomic effects (17). It is reported that dexamethasone can suppress inflammatory processes and ROS production (18). Dexamethasone is known to decrease $\mathrm{I} / \mathrm{R}$ injury in different organs (19). The aim of this research was to study combination pretreatment with melatonin and dexamethasone in reducing hepatic $\mathrm{I} / \mathrm{R}$ injury in rat.

\section{Materials and methods}

\section{Animals}

Male Wistar rats were obtained from Laboratory Animal Care Center of Tabriz University of Medical Sciences (Tabriz, Iran). Rats weighed 240-285 g and were approximately 6-7 weeks old. Fluorescent lights were on for $12 \mathrm{~h} /$ day. The experiments were performed according to the guidelines of our Ethics Committee. After an adaptation period of 3 days, rats $(n=60)$ were assigned to 5 groups of 12 animals each: (Group 1) Sham: injected with ( $0.9 \%$ saline); (Group 2) I/R: injected with $0.9 \%$ saline and subjected to hepatic I/R; (Group 3) I/R+MEL: hepatic I/R+ melatonin (20 mg/kg) injected intraperitoneally (i.p.); (Group 4) I/R+DEX: hepatic $\mathrm{I} / \mathrm{R}+$ dexamethasone $(10 \mathrm{mg} / \mathrm{kg})$ injected intravenously (i.v.); (Group 5) I/R+MEL+DEX: hepatic I/R+ melatonin (20 mg/ $\mathrm{kg})$ injected intraperitoneally (i.p) + dexamethasone $(10 \mathrm{mg} / \mathrm{kg})$ injected intravenously (i.v).

\section{Melatonin treatment}

Melatonin (MEL) was purchased from Merck Chemical Co (Darnstadt, Germany). MEL was freshly dissolved in absolute etha- nol and further dilutions were made in saline. The final concentration of ethanol was $1 \%$. A volume of ethanol equal to that used in the MEL solution was added to the saline solution. MEL was administered intraperitoneally (i.p.) at $20 \mathrm{mg} / \mathrm{kg}, 1 \mathrm{~h}$ prior to the trial.

\section{Dexamethasone treatment}

Dexamethasone was administered as a single injection of 10 $\mathrm{mg} / \mathrm{kg}$. The drug was injected intravenously (i.v.), $20 \mathrm{~min}$ before the trial.

\section{Surgery protocol}

Rats were anesthetized with ketamin $(50 \mathrm{mg} / \mathrm{kg})$ and xylazine $(10 \mathrm{mg} / \mathrm{kg})$. They were placed in a supine position. After midline laparotomy, the liver was made ischemic by clamping both the portal vein and hepatic artery. After $30 \mathrm{~min}$ of ischemia, the clamp was released to allow reperfusion of the liver for 6 hours. The abdominal cavity was closed, and the animals were allowed to recover with free access to food and water. After $6 \mathrm{~h}$, rats were anesthetized and serum was obtained for biochemical analysis (20). At laparotomy, liver tissue samples were excised from the same region of the liver to determine biomarkers of oxidative stress and perform histopathologic examination.

\section{Assay of antioxidant enzymes}

The left lobe of liver was frozen in liquid nitrogen and stored at $-80{ }^{\circ} \mathrm{C}$ until further preparation. In order to measure anti-oxidant enzyme activity, the liver samples were homogenized in $1.15 \%$ $\mathrm{KCl}$ solution. Superoxide dismutase ( SOD) activity in liver tissue was determined by using xanthine and xanthine oxidase to generate superoxide radicals which then react with 2-(4-iodophenyl)-3-(4nitrophenol)-5-phenyltetrazolium chloride to form a red formazan dye. The SOD activity was then measured by the degree of inhibition of this reaction (Ransod, Randox Laboratories Ltd., Antrim, United Kingdom). Results were obtained as SOD Unit/mg protein (21).

Glutathione peroxidase (GPx) activity in liver tissue was measured using the method described by Paglia and Valentine. GPx catalyses the oxidation of glutathione by cumene hydroperoxide. In the presence of glutathione reductase and NADPH, the oxidized glutathione is immediately converted to a reduced form with a concomitant oxidation of NADPH to $\mathrm{NADP}^{+}$. The decrease in absorbance at $340 \mathrm{~nm}$ is measured (Ransod, Randox Laboratories Ltd., Antrim, UK). Results obtained as GPx Unit/mg protein (22).

\section{Tissue MDA level}

Tissue malondialdehyde was determined by the method of Uchiyama and Mihara (23). A 3-mL aliquot of $1 \%$ phosphoric acid and $1 \mathrm{~mL}$ of $0.6 \%$ thiobarbituric acid solution were added to $0.5 \mathrm{~mL}$ of $10 \%$ tissue homogenate. The mixture was heated in boiling water for 45 minutes. After cooling, the color was extracted into $4 \mathrm{~mL}$ of $\mathrm{n}$-butanol. The absorbance was measured in a spectrophotometer (Amersham Pharmacia Biotech UK Ltd., Little Chalfont, Buckinghamshire, UK) at $532 \mathrm{~nm}\left(\dot{\varepsilon}=.56 \times 10^{5} \mathrm{~mol} / \mathrm{L}^{-1}\right.$ $\mathrm{cm}^{-1}$ ). The amounts of lipid peroxides calculated as thiobarbituric acid reactive substances (TBARS) of lipid peroxidation were expressed as $\mathrm{nMol} / \mathrm{ml}(24)$. 


\section{Serum biochemistry}

Serum alanine aminotransferase (ALT) and aspartate aminotransferase (AST) activities were measured to assess hepatic function. ALT and AST activities were measured using diagnostic kits (Pars Azmoon, Tehran, Iran). The samples were centrifuged at $1000 \mathrm{~g}$ for $10 \mathrm{~min}$ within $1 \mathrm{~h}$ after collection. The sera had been stored in a freezer at $-80{ }^{\circ} \mathrm{C}$ before they were analyzed. Enzyme activities of serum ALT and AST were evaluated by an auto analyzer (ALCYON 300-Abbott, USA) (25).

\section{ELISA assay for TNF- $\alpha$}

Plasma level of tumor necrosis factor-alpha (TNF- $\alpha$ ) was measured by an enzyme-linked immunoadsorbent assay (ELISA) using rat serum TNF- $\alpha$ immunoassay kit (Bender Med Systems, Vienna, Austria).

\section{Histopathology}

Liver tissue samples were saved and fixed in $10 \%$ formalin. Paraffin-embedded liver tissue was cut into 5- $\mu \mathrm{m}$ thick sections, deparaffinized in xylene, and rehydrated through a series of decreasing concentrations of ethanol. The sections were stained with hematoxylin and eosin and analyzed under a light microscope. The liver samples were then graded histologically according to the severity of injury by using a predetermined scoring system for liver tissue. The assessment was expressed as sum of the individual score grades from 0 (no findings), 1 (mild), 2 (moderate), to 3 (severe) for each of the following 6 parameters from liver sections: cytoplasmatic color fading, vacuolization, nuclear condensation, nuclear fragmentation, nuclear fading, and erythrocyte stasis (26).

\section{TUNEL assay}

Terminal deoxynucleotidyl transferase-mediated dUTP nick-end labelling (TUNEL) assay was used to assess the DNA fragmentation in paraffin-embedded tissue sections. The assay was conducted according to the manufacturer's instructions (Roche,Mannheim,Germany). The total of cell population and TUNEL-positive cells were counted. TUNEL positive cells were expressed as percentage of total cells.

\section{Statistical analysis}

Data were expressed as means $\pm \mathrm{SD}$. The differences among various groups were tested for statistical significance using the one-way ANOVA test and Tukeys post test. A p value of less than 0.05 denoted the presence of a statistically significant difference.

\section{Results}

\section{SOD and GPx level}

Level of SOD and GPx antioxidant enzymes were decreased in all of the groups subjected to hepatic $I / R$, but it was less severe in melatonin- and dexamethasone-pretreated groups. SOD and GPx levels in $\mathrm{I} / \mathrm{R}+\mathrm{MEL}+\mathrm{DEX}$ group were higher than those in $\mathrm{I} /$ $\mathrm{R}+\mathrm{MEL}$ and $\mathrm{I} / \mathrm{R}+\mathrm{DEX}$ groups, and in $\mathrm{I} / \mathrm{R}+\mathrm{MEL}$ group they were significantly higher than in $\mathrm{I} / \mathrm{R}+\mathrm{DEX}$ group $(\mathrm{p}<0.05)($ Tab. 1$)$.

\section{MDA level}

MDA level, as an index of lipid peroxidation, increased significantly in all of the groups subjected to hepatic I/R. MDA level was significantly lower in $\mathrm{I} / \mathrm{R}+\mathrm{MEL}+\mathrm{DEX}$ group compared to I/ $\mathrm{R}+$ MEL group and $\mathrm{I} / \mathrm{R}+\mathrm{DEX}$ group $(\mathrm{p}<0.05)$ and it was significantly lower in $\mathrm{I} / \mathrm{R}+\mathrm{MEL}$ group compared to $\mathrm{I} / \mathrm{R}+\mathrm{DEX}$ group ( $\mathrm{p}$ $<0.05$ ) (Tab. 1).

\section{Liver function}

At 6 hours post I/R, serum ALT and AST levels were significantly lower in the $\mathrm{I} / \mathrm{R}+\mathrm{MEL}+\mathrm{DEX}, \mathrm{I} / \mathrm{R}+\mathrm{MEL}$ and $\mathrm{I} / \mathrm{R}+\mathrm{DEX}$ groups compared to I/R group $(p<0.05)$. Levels of ALT and AST were lower in $\mathrm{I} / \mathrm{R}+\mathrm{MEL}$ group compared to $\mathrm{I} / \mathrm{R}+\mathrm{DEX}$ group, and their levels were significantly lower in $\mathrm{I} / \mathrm{R}+\mathrm{MEL}+\mathrm{DEX}$ group compared to $\mathrm{I} / \mathrm{R}+\mathrm{MEL}$ and $\mathrm{I} / \mathrm{R}+\mathrm{DEX}$ groups $(\mathrm{p}<0.05)($ Tab. 2$)$.

\section{Histological changes}

At 6 hours post I/R, we observed the following events in hepatic tissue of the I/R group: cytoplasmatic color fading, vacuolization, nuclear condensation, nuclear fragmentation, nuclear fading, and erythrocyte stasis. Liver tissue injury index in I/R group was significantly higher than that in $\mathrm{I} / \mathrm{R}+\mathrm{MEL}, \mathrm{I} / \mathrm{R}+\mathrm{DEX}$ and $\mathrm{I} / \mathrm{R}+\mathrm{MEL}+\mathrm{DEX}$ groups. Tissue injury index in $\mathrm{I} / \mathrm{R}+\mathrm{MEL}$ group was lower than $\mathrm{I} /$ $\mathrm{R}+\mathrm{DEX}$ group, and in $\mathrm{I} / \mathrm{R}+\mathrm{MEL}+\mathrm{DEX}$ group it was significantly lower than in I/R+ MEL and I/R+DEX groups $(\mathrm{p}<0.05)($ Tab. 3$)$.

\section{Apoptosis}

A significant increase in the number of TUNEL-positive cells $(p<0.05)$ was observed in rats undergoing $\mathrm{I} / \mathrm{R}$. The MEL and

Tab. 1. The effect of melatonin, dexamethasone and their combination on hepatic antioxidant enzymes content and MDA levels in rat liver after ischemia/reperfusion.

\begin{tabular}{lclcc}
\hline & I/R+MEL+DEX & I/R+DEX & I/R+MEL & Hepatic I/R \\
\hline SOD (U/mg protein) & $3.62 \pm 0.32$ & $1.72 \pm 0.41$ & $2.84 \pm 0.46$ & $1.14 \pm 0.27$ \\
GPX (U/mg protein) & $3.44 \pm 0.35$ & $2.08 \pm 0.18$ & $2.71 \pm 0.41$ & $1.24 \pm 0.42$ \\
MDA (nMol/ml) & $2.83 \pm 0.21$ & $4.19 \pm 0.42$ & $3.36 \pm 0.34$ & $5.15 \pm 0.39$ \\
\hline
\end{tabular}

The rat liver was pretreated with melatonin $(20 \mathrm{mg} / \mathrm{kg})$ or dexamethasone $(10 \mathrm{mg} / \mathrm{kg})$ or with a combination of them prior to ischemia. The livers were subjected to $30 \mathrm{minutes}$ of ischemia followed by 6 hours of reperfusion. The values are shown as a mean \pm SD for rats in each group and difference of $\mathrm{p}<0.05$ was considered significant. Level of SOD and GPx antioxidant enzymes were decreased in all of the groups subjected to hepatic I/R, but it was less severe in melatonin- and dexamethasone-pretreated groups. SOD and GPx levels in $\mathrm{I} / \mathrm{R}+\mathrm{MEL}+\mathrm{DEX}$ group were higher than in $\mathrm{I} / \mathrm{R}+\mathrm{MEL}$ and $\mathrm{I} / \mathrm{R}+\mathrm{DEX}$ groups, and in $\mathrm{I} / \mathrm{R}+\mathrm{MEL}$ group they were significantly higher than in $\mathrm{I} / \mathrm{R}+\mathrm{DEX}$ group $(\mathrm{p}<0.05)$. MDA level as an index of lipid peroxidation increased significantly in all of the groups subjected to hepatic $\mathrm{I} / \mathrm{R}$. MDA level was significantly lower in $\mathrm{I} /$ $\mathrm{R}+\mathrm{MEL}+\mathrm{DEX}$ group compared to that in $\mathrm{I} / \mathrm{R}+\mathrm{MEL}$ group and $\mathrm{I} / \mathrm{R}+\mathrm{DEX}$ group $(\mathrm{p}<0.05)$, and it was significantly lower in $\mathrm{I} / \mathrm{R}+\mathrm{MEL}$ group compared to $\mathrm{I} / \mathrm{R}+\mathrm{DEX}$ group $(\mathrm{p}<0.05)$. I/R+MEL: ischemia/reperfusion+melatonin, I/R+DEX: ischemia/reperfusion+dexamethasone, I/R+MEL+DEX: ischemia/reperfusion+melatonin+dexamethasone, SOD: Superoxide dismutase, GPx: Glutathione peroxidase, MDA: Malondialdehyde. 
Tab. 2. The effect of melatonin, dexamethasone and their combination on serum ALT, AST and TNF- $\alpha$ levels in rat liver after ischemia/reperfusion.

\begin{tabular}{lccccc}
\hline & Sham & Hepatic I/R & I/R+MEL & I/R+DEX & I/R+MEL+DEX \\
\hline ALT (U/L) & $31.37 \pm 5.92$ & $258.25 \pm 29.62$ & $159.37 \pm 15.01$ & $213.75 \pm 14.58$ & $118.25 \pm 15.19$ \\
AST (U/L) & $83.12 \pm 6.81$ & $833.25 \pm 35.49$ & $578.87 \pm 53.64$ & $762.00 \pm 37.99$ & $471.25 \pm 31.24$ \\
TNF- $\alpha(\mathrm{pg} / \mathrm{ml})$ & $19.12 \pm 3.68$ & $117.12 \pm 8.27$ & $93.37 \pm 9.94$ & $76.37 \pm 12.67$ & $53.75 \pm 7.20$ \\
\hline
\end{tabular}

The rat liver was pretreated with melatonin $(20 \mathrm{mg} / \mathrm{kg}$ ) or dexamethasone $(10 \mathrm{mg} / \mathrm{kg})$ or with a combination of them prior to ischemia. The livers were subjected to $30 \mathrm{minutes}$ of ischemia followed by 6 hours of reperfusion. The values are shown as a mean \pm SD for rats in each group and difference of $p<0.05$ was considered significant. At 6 hours post I/R, serum ALT,AST and TNF- $\alpha$ levels were significantly lower in I/R+MEL+DEX, I/R+MEL and I/R+DEX groups compared to I/R group ( $p<0.05)$. Levels of ALT, AST and TNF- $\alpha$ were lower in $\mathrm{I} / \mathrm{R}+\mathrm{MEL}$ group compared to those in $\mathrm{I} / \mathrm{R}+\mathrm{DEX}$ group, and their levels were significantly lower in $\mathrm{I} / \mathrm{R}+\mathrm{MEL}+\mathrm{DEX}$ group compared to those in $\mathrm{I} / \mathrm{R}+\mathrm{MEL}$ and $\mathrm{I} / \mathrm{R}+\mathrm{DEX}$ groups $(\mathrm{p}<0.05)$. I/R+MEL: ischemia/reperfusion+melatonin, $\mathrm{I} / \mathrm{R}+\mathrm{DEX}$ : ischemia/reperfusion+dexamethasone, $\mathrm{I} / \mathrm{R}+\mathrm{MEL}+\mathrm{DEX}$ : ischemia/reperfusion+melatonin+dexamethasone, ALT: alanine aminotransferase, AST: aspartate aminotransferase, TNF- $\alpha$ : tumor necrosis factor-alpha.

Tab. 3. The effect of melatonin, dexamethasone and their combination on liver tissue injury index and percentage of TUNEL positive cells in the rat liver after ischemia / reperfusion.

\begin{tabular}{lccccc}
\hline & Sham & Hepatic I/R & I/R+MEL & I/R+DEX & I/R+MEL+DEX \\
\hline Liver tissue injury index & $0.62 \pm 0.51$ & $15.25 \pm 1.03$ & $10.12 \pm 1.12$ & $12.37 \pm 0.91$ & $8.25 \pm 1.03$ \\
\%TUNEL positive cells & $2.40 \pm 1.14$ & $21.40 \pm 2.07$ & $13.40 \pm 1.34$ & $17.60 \pm 2.40$ & $9.60 \pm 1.81$ \\
\hline
\end{tabular}

The rat liver was pretreated with melatonin $(20 \mathrm{mg} / \mathrm{kg})$ or dexamethasone $(10 \mathrm{mg} / \mathrm{kg})$ or with combination of them prior to ischemia. Livers were subjected to $30 \mathrm{minutes}$ of ischemia followed by 6 hours of reperfusion. The values are shown as a mean \pm SD for rats in each group and difference of $p<0.05$ was considered significant. Liver tissue injury index and percentage of TUNEL-positive cells in $\mathrm{I} / \mathrm{R}$ group was significantly higher than in $\mathrm{I} / \mathrm{R}+\mathrm{MEL}, \mathrm{I} / \mathrm{R}+\mathrm{DEX}$ and $\mathrm{I} / \mathrm{R}+\mathrm{MEL}+\mathrm{DEX}$ groups, While in $\mathrm{I} /$ $\mathrm{R}+\mathrm{MEL}$ group it was lower than in $\mathrm{I} / \mathrm{R}+\mathrm{DEX}$ group, in $\mathrm{I} / \mathrm{R}+\mathrm{MEL}+\mathrm{DEX}$ group it was significantly lower than in $\mathrm{I} / \mathrm{R}+\mathrm{MEL}$ and $\mathrm{I} / \mathrm{R}+\mathrm{DEX}$ groups. $\mathrm{I} / \mathrm{R}+\mathrm{MEL}$ : ischemia/ reperfusion+melatonin, I/R+DEX: ischemia/reperfusion+dexamethasone, I/R+MEL+DEX: ischemia/reperfusion+ melatonin+ dexamethasone.

DEX treatment led to a significant decrease in the number of TUNEL-positive cells compared with $\mathrm{I} / \mathrm{R}$ group. The number of TUNEL-positive cells was significantly higher in $\mathrm{I} / \mathrm{R}+\mathrm{DEX}$ group compared to MEL $+\mathrm{I} / \mathrm{R}$ group. However, a smaller number of TUNEL-positive cells was observed in the group receiving both MEL and DEX $(\mathrm{p}<0.05)$.

\section{$T N F-\alpha$ level}

TNF- $\alpha$ level as an inflammatory mediator was significantly increased after hepatic I/R in all of the groups $(\mathrm{p}<0.05)$. TNF- $\alpha$ level was lower in I/R+MEL+DEX group than in $\mathrm{I} / \mathrm{R}, \mathrm{I} / \mathrm{R}+\mathrm{MEL}$ and $\mathrm{I} / \mathrm{R}+\mathrm{DEX}$ groups, and in $\mathrm{I} / \mathrm{R}+\mathrm{DEX}$ group it was lower than in $\mathrm{I} / \mathrm{R}+\mathrm{MEL}$ and $\mathrm{I} / \mathrm{R}$ groups, while in $\mathrm{I} / \mathrm{R}+\mathrm{MEL}$ group it was significantly lower than in $\mathrm{I} / \mathrm{R}$ group $(\mathrm{p}<0.05)$ (Tab. 2$)$.

\section{Discussion}

Liver I/R injury occurs in a biphasic pattern, consisting of both acute and subacute phase responses. The acute phase is characterized by hepatocellular injury after 3 to $6 \mathrm{~h}$ of reperfusion, and is associated with the generation of free radicals. The subacute phase response following liver I/R is characterized by massive neutrophil infiltration, peaking after 18 to $24 \mathrm{~h}$ of reperfusion $(27,28)$. Until now there is a lack of clinical trials that describe pharmacological preconditioning of the liver to protect against I/R injury. Moreover, established strategies, such as ischemic preconditioning, lose their potential in patients over 60 years of age or in cases of high volume liver resection (29). Our current study points to melatonin as an effective anti-oxidant and dexamethasone as a potent antiinflammatory agent to protect against hepatic I/R injury. Interestingly, hepatocyte injury clearly occurs in the course of ischemia as it has previously been shown in experimental animal studies (30). These findings support the necessity for interventions against $I / R$ injury to begin before the onset of ischemia. Strategies that con- centrate on blocking one pathway of reperfusion injury, such as enhancement of antioxidant enzymes or using anti-inflammatory agents, may not be sufficient because a variety of cellular pathways are involved in the injury cascade (31). Previous studies had shown salutary effects of melatonin and dexamethasone in restoring organ or cell functions after hepatic I/R $(16,19)$. In this study we assessed liver injury using biochemical analysis and light microscopy. Our data strongly support the hypothesis that combined administration of melatonin and dexamethasone reduces hepatic $\mathrm{I} / \mathrm{R}$ injury more effectively than administering each of these drugs alone. The protection is facilitated by preservation of cellular antioxidant enzymes levels in liver tissue and characterized by reduced hepatocyte injury and plasma TNF- $\alpha$ level upon melatonin and dexamethasone preconditioning. The production of reactive oxygen substances leads to hepatocyte damage; therefore poor liver function becomes even worse (32). Previous studies suggest that free radicals formed during reperfusion are involved in the mechanism of graft failure following liver transplantation in the rat (33). Moreover, oxidative stress is found to have sustained for a long time after clinical liver transplantation (34) and linked with primary nonfunctioning graft (35). Although the role of ROS in hepatic I/R has been reported, the detailed mechanisms are unclear. The most convincing hypothesis of ROS-induced cell injury is the destruction of the cellular membranes via lipid peroxidation (36).

To reduce the detrimental effects of ROS, besides diminishing its production, organisms have developed their own antioxidant mechanisms including low-molecular-weight antioxidant molecules, i.e. glutathione, melatonin, and various antioxidant enzymes such as SOD, GPx, and glutathione reductase. These enzymes activities are higher in the liver than in other tissues (37). Superoxide dismutase (SOD), an oxygen radical scavenger, which converts the superoxide anion radical present in the upper stream of reactive oxygen metabolism cascade, will afford protection from cell damage. There were reports describing the efficacy of 
SOD on I/R injury of the liver (38). SOD catalyses the dismutation of the superoxide anion $\left(\mathrm{O}_{2}^{-}\right)$into $\mathrm{H}_{2} \mathrm{O}_{2}$; GSH-Px is a selenoprotein, which reduces lipidic or nonlipidic hydroperoxides as well as $\mathrm{H}_{2} \mathrm{O}_{2}$ while oxidizing GSH (39). In our study, we found that $\mathrm{I} / \mathrm{R}$ impaired these enzymes activities, as indicated by the markedly lower activities when compared with sham group. But in I/ $\mathrm{R}+\mathrm{MEL}+\mathrm{DEX}, \mathrm{I} / \mathrm{R}+\mathrm{MEL}$ and $\mathrm{I} / \mathrm{R}+\mathrm{DEX}$ groups, the decrease in enzymes activities was significantly suppressed during I/R injury. At the same time however it was more effective in I/R+MEL+DEX group than in $\mathrm{I} / \mathrm{R}+\mathrm{MEL}$ and $\mathrm{I} / \mathrm{R}+\mathrm{DEX}$ groups; these data indicate that the combined administration of melatonin and dexamethasone may confer better protection to the liver during $\mathrm{I} / \mathrm{R}$ injury. ROS is involved in I/R injury. The liver contents of MDA, the product of lipid peroxidation, significantly increased following $I / R$ compared with sham group. In $\mathrm{I} / \mathrm{R}+\mathrm{MEL}+\mathrm{DEX}$ group, the MDA contents was markedly lowered compared with I/R, I/R+MEL and $\mathrm{I} / \mathrm{R}+\mathrm{DEX}$ groups. The results are in agreement with the reports of Zhang et al (40). They have shown that dexamethasone could block ROS generation, thus providing the protection against liver I/R injury through suppressing the MDA level. Kaçmaz et al, have reported that melatonin decreases the MDA level and our results are in agreement with their report (41). The improvement in antioxidant system with dexamethasone pretreatment was in agreement with Ozturk et al (42), although there are some reports such as that of Oshima et al (43) indicating oxidative effect of dexamethasone. In fact, corticosteroids have been shown to inhibit the generation of oxygen free radicals and to reduce hepatic ischemia-reperfusion injury (44). In the present study, the dexamethasone pretreatment enhanced the antioxidant enzyme level but this enhancement was more effective through melatonin pretreatment than through dexamethasone pretreatment, while the combination therapy was more effective than the administration of any of these drugs alone.

The clamping period was set exactly at $30 \mathrm{~min}$. This period is the shortest ischemic time associated with elevated hepatic transaminases levels after surgery (45). Enzymes such as ALT and AST are used as markers of cellular damage following hepatic $\mathrm{I} / \mathrm{R}$ injury. The levels persist for some period during reperfusion and then return to normal levels (46). In our study, the serum AST and ALT levels of the I/R+ MEL+DEX group were significantly lower than in $\mathrm{I} / \mathrm{R}+\mathrm{MEL}$ or $\mathrm{I} / \mathrm{R}+\mathrm{DEX}$ groups. This suggests that combined treatment with melatonin and dexamethasone decreases hepatic cellular damage. These effects may be due to strong antioxidative properties of melatonin and anti-inflammatory activity of dexamethasone. We observed an increase in histomorphological features of hepatocyte injury in the non-treated group which was in accordance with our previous study (20). We observed necrosisrelated cell death after $30 \mathrm{~min}$ of ischemia and $6 \mathrm{~h}$ of reperfusion. Light microscopic studies showed that $30 \mathrm{~min}$ of hepatic ischemia followed by reperfusion is associated with marked changes (20). In our study, $30 \mathrm{~min}$ of ischemia followed by $6 \mathrm{~h}$ of reperfusion caused severe sinusoidal congestion and cytoplasmic vacuolization in midzonal areas. The changes were less marked in I/R+ MEL and I/R+DEX groups, but these changes were less severe in $\mathrm{I} / \mathrm{R}+\mathrm{MEL}+\mathrm{DEX}$ group compared to $\mathrm{I} / \mathrm{R}+\mathrm{MEL}$ and $\mathrm{I} / \mathrm{R}+\mathrm{DEX}$ groups. These results show the beneficial effects of combined pretreatment with melatonin and dexamethasone on hepatic I/R injury at the cellular level. The relationship between hepatic $\mathrm{I} / \mathrm{R}$ injury and inflammatory mediators has received much attention in recent years (47).

Apoptosis has been regarded as a central mechanism of injury for liver WI/R (48). Apoptosis is initiated via two pathways: (1) the process begins through the release of cytochrome from mitochondria after cellular stress; (2) the other pathway is Fas/ FasLdependent (49). A cellular surface molecule belonging to the tumor necrosis factor family binds to its receptor, Fas, to form the death complex that then activates a class of initiator caspases (50). Therefore the agents which could be able to suppress TNF- $\alpha$ production and scavenge free radicals may reduce apoptosis. Both MEL and DEX decreased the number of apoptotic cells but MEL administration was more effective than DEX in reducing the number of apoptotic cells. However the combined treatment with MEL and DEX had better effects compared to administration of MEL or DEX alone. Evidence indicates that a severe inflammatory reaction is evoked after hepatic I/R injury and leads to histological changes (51). TNF- $\alpha$ plays an important role in this process. TNF- $\alpha$, a key cytokine in the pathogenesis of I/R injury, is a polypeptide hormone that has a wide range of biological activities (52). TNF- $\alpha$ does not exist in a stored form but is rather synthesized after cellular activation by a number of cells, including monocytes/macrophages, lymphocytes, Kupffer cells, cardiomyocytes and others $(52,53)$. TNF- $\alpha$ was shown to be synthesized and released in the human liver at the time of hepatic ischemia (54). Some mechanisms were used to explain the liver damage caused by TNF- $\alpha$. Firstly, TNF- $\alpha$ could directly injure hepatocytes. Secondly, TNF- $\alpha$ could activate neutrophilic granulocytes and mononuclear macrophages to express IL-1 and IL-6, and phosphatidase A2 that can decompose arachidonic acids. Inflammatory mediators were produced, such as platelet activation factor, leukotriene, and thromboxane A2, thus aggravating the inflammatory reaction. Thirdly, the toxic effect of TNF- $\alpha$ on endothelial cells could induce a circulatory disorder of hepatic sinusoid, and TNF- $\alpha$ could activate a complement system that aggravates tissue damage by cytotoxicity. Finally, the oxygen-derived free radicals induced by TNF $\alpha$ could facilitate an oxidative burst of neutrophilic granulocytes, which could also result in liver damage. Therefore, the way to block the production of TNF- $\alpha$ in the liver can be used to prevent liver from injury by TNF- $\alpha$ (55). Kurcer et al (56) have reported that melatonin has no effect on TNF- $\alpha$ level in I/R process, but in our study melatonin decreased TNF $\alpha$ level, and this result was in agreement with Rodríguez-Reynoso et al (57) who report that melatonin administration decreases TNF- $\alpha$ level. However this suppression in TNF- $\alpha$ level in $\mathrm{I} / \mathrm{R}+\mathrm{MEL}$ group was less effective compared to that in $\mathrm{I} / \mathrm{R}+\mathrm{DEX}$ group, while dexamethasone administration had a better suppression effect on TNF- $\alpha$ level, and in I/R+MEL+DEX it suppressed TNF $\alpha$ more effectively than in $\mathrm{I} / \mathrm{R}+\mathrm{MEL}$ and $\mathrm{I} / \mathrm{R}+\mathrm{DEX}$ groups.

Presman et al (58) have reported that melatonin administration could reduce the affinity of glucocorticoid receptors and increase the sensitivity to glucocorticoid feedback, and this may be one of the mechanisms that expresses the synergism effect by MEL and DEX combination therapy. 
47-53

\section{Conclusions}

In summary, the elevation of liver aminotransferases, TNF- $\alpha$ level and liver tissue injury were attenuated through melatonin and dexamethasone pretreatment but the administration of combined treatment with melatonin and dexamethasone offered better protection when compared to the administration of melatonin or dexamethasone alone in rat model of hepatic I/R. Cellular antioxidant enzymes were improved by the administration of melatonin and dexamethasone; however, the combination therapy had better effects. While dexamethasone is usually used for suppressing inflammation and melatonin is an endogenous anti-oxidant with not so many side effects, the combined therapy of these two drugs may be a safe and effective protocol of protecting against the hepatic I/R injury.

\section{References}

1. Pringle JH. Notes on the arrest of hepatic hemorrhage due to trauma. Ann Surg 1908; 48: 541-549.

2. Pannen BH. New insights into the regulation of hepatic blood flow after ischemia and reperfusion. Anesth Analg 2002; 94: 1448-1457.

3. Ramalho FS, Fernandez-Monteiro I, Rosello-Catafau J, Peralta C. Hepatic microcirculatory failure. Acta Cir Bras 2006; 21: 48-53.

4. Jaeschke H. Mechanism of reperfusion injury after warm ischemia of the liver. J Hepatol 1998; 21: 402-408.

5. Colletti LM, Remick DG, Burtch GD, Kunkel SL, Strieter RM, Campbell DA Jr. Role of tumor necrosis factor-alpha in the pathophysiologic alterations after hepatic ischemia/reperfusion injury in the rat. J Clin Invest 1990; 85: 1936-1943.

6. Lentsch AB, Kato A, Yoshidome H, McMasters KM, Edwards MJ. Inflammatory mechanisms and therapeutic strategies for warm hepatic ischemia/reperfusion injury. Hepatology 2000; 32: 169-173.

7. Jaeschke H, Bautista AP, Spolarics Z, Spitzer JJ. Superoxide generation by Kupffer cells and priming of neutrophils during reperfusion after hepatic ischemia. Free Radic Res Commun 1991; 15: 277-284.

8. Jaeschke H, Farhood A. Kupffer cell activation after no-flow ischemia versus hemorrhagic shock. Free Radic Biol Med 2002; 33: 210-219.

9. Gonzalez-Flecha B, Cutrin JC, Boveris A. Time course and mechanism of oxidative stress and tissue damage in rat liver subjected to in vivo ischemia-reperfusion. J Clin Invest 1993; 91: 456-464.

10. Polat KY, Aydinli B, Polat O, Aydin U, Yazici P, Ozturk G, Gundogdu C, Kiziltunc A. The protective effect of aprotinin and alpha-tocopherol on ischemia-reperfusion injury of the rat liver. Transplant Proc 2008; 40: 63-68.

11. Pei Z, Pang SF, Cheung RT. Administration of melatonin after onset of ischemia reduces the volume of cerebral infarction in a rat middle cerebral artery occlusion stroke model. Stroke. 2003; 34: 770-775.

12. Othman AI, El-Missiry MA, Amer MA, Arafa M. Melatonin controls oxidative stress and modulates iron, ferritin, and transferrin levels in adriamycin treated rats. Life Sci 2008; 83: 563-568.

13. Kedziora-Kornatowska K, Szewczyk-Golec K, Czuczejko J, Pawluk H, van Marke de Lumen K, Kozakiewicz M, Bartosz G, Kedziora J. Antioxidative effects of melatonin administration in elderly primary essential hypertension patients. J Pineal Res. 2008; 45: 312-317.
14. Jaworek J, Nawrot-Porabka K, Leja-Szpak A, Bonior J, Szklarczyk J, Kot M, Konturek SJ, Pawlik WW. Melatonin as modulator of pancreatic enzyme secretion and pancreatoprotector. J Physiol Pharmacol 2007; 58: 65-80.

15. Vairetti M, Ferrigno A, Bertone R, Rizzo V, Richelmi P, Bertè F, Reiter RJ, Freitas I. Exogenous melatonin enhances bile flow and ATP levels after cold storage and reperfusion in rat liver: implications for liver transplantation. J Pineal Res 2005; 38: 223-230.

16. Baykara B, Tekmen I, Pekcetin C, Ulukus C, Tuncel P, Sagol O, Ormen M, Ozogul C. The protective effects of carnosine and melatonin in ischemia-reperfusion injury in the rat liver. Acta Histochem 2009; 111: 42-51.

17. Odermatt A, Gumy C. Glucocorticoid and mineralocorticoid action: why should we consider influences by environmental chemicals? Biochem Pharmacol 2008; 76: 1184-1193.

18. Simons SS Jr. What goes on behind closed doors: physiological versus pharmacological steroid hormone actions. Bioessays 2008; 30: 744-756.

19. Morariu AM, Loef BG, Aarts LP, Rietman GW, Rakhorst G, van Oeveren W, Epema AH. Dexamethasone: benefit and prejudice for patients undergoing on-pump coronary artery bypass grafting: a study on myocardial, pulmonary, renal, intestinal, and hepatic injury. Chest 2005; 128: $2677-2687$.

20. Dibazar F, Hajipour B, Hosseinian MM, Hemmati MR, Ghandiha A. Simvastatin decreases hepatic ischaemia/reperfusion-induced liver and lung injury in rats. Folia Morphol 2008; 67: 231-235.

21. Paoletti F, Aldinucci D, Mocali A, Caparrini A. A sensitive spectrophotometric method for the determination of superoxide dismutase activity in tissue extracts. Anal Biochem 1986; 154: 536-541.

22. Paglia DE, Valentine WN. Studies on the quantitative and qualitative characterization of erythrocyte glutathione peroxidase. J Lab Clin Med 1967; 70: 158-169.

23. Mihara M, Uchiyama M. Effects of antioxidants on the TBA reaction of various rat liver homogenates, Biochem Med 1983; 30: 131.

24. Kirimlioglu H, Ecevit A, Yilmaz S, Kirimlioglu V, Karabulut AB. Effect of resveratrol and melatonin on oxidative stress enzymes, regeneration, and hepatocyte ultrastructure in rats subjected to $70 \%$ partial hepatectomy. Transplant Proc 2008; 40: 285-289.

25. Lee KJ, Choi JH, Khanal T, Hwang YP, Chung YC, Jeong HG. Protective effect of caffeic acid phenethyl ester against carbon tetrachlorideinduced hepatotoxicity in mice. Toxicology 2008; 248: 18-24.

26. Jiang H, Meng F, Li W, Tong L, Qiao H, Sun X. Splenectomy ameliorates acute multiple organ damage induced by liver warm ischemia reperfusion in rats. Surgery 2007; 141: 32-40.

27. Zwacka RM, Zhang Y, Halldorson J, Schlossberg H, Dudus L, Engelhardt JF. CD4(+) T-lymphocytes mediate ischemia/reperfusion-induced inflammatory responses in mouse liver. J Clin Invest 1997; 100: 279.

28. Lee WY, Lee JS, Lee SM. Protective effects of combined ischemic preconditioning and ascorbic acid on mitochondrial injury in hepatic ischemia/reperfusion. J Surg Res 2007; 142: 45-52.

29. Clavien PA, Selzner M, Rüdiger HA, Graf R, Kadry Z, Rousson V, Jochum W. A prospective randomized study in 100 consecutive patients undergoing major liver resection with versus without ischemic preconditioning. Ann Surg 2003; 238: 843-850.

30. Soeda J, Miyagawa S, Sano K, Masumoto J, Taniguchi S, Kawasaki S. Cytochrome c release into cytosol with subsequent caspase activation 
during warm ischemia in rat liver. Am J Physiol Gastrointest Liver Physiol 2001; 281: 1115-1123.

31. Dünschede F, Erbes K, Kircher A, Westermann S, Seifert J, Schad A, Oliver K, Kiemer AK, Theodor J. Reduction of ischemia reperfusion injury after liver resection and hepatic inflow occlusion by $\alpha$-lipoic acid in humans. World J Gastroenterol 2006 14; 12: 6812-6817.

32. Rutkowski T, Plewka A, Kaminski M. Study on ischemic/reperfusion damage to the liver: Hitherto existing successes and defeats. Acta Polo Toxicol 2000; 8: 1-15

33. Henry DC, Wenshi G, Sadayuki N. Evidence that free radicals are involved in graft failure following orthotopic liver transplantation in the rat-an electron paramagnetic resonance spin trapping study. Transplantation 1992; 54: 199-204.

34. Burke A, FitzGerald GA, Lucey MR. A prospective analysis of oxidative stress and liver transplantation. Transplantation 2002; 74: 217-221.

35. Atalla SL, Toledo-Pereyra LH, MacKenzie GH, Cederna JF. Influence of oxygen-derived free radical scavengers on ischemic livers. Transplantation 1985; 40: 584-590.

36. Omar R, Nomikos I, Piccorelli G. Prevention of postischemic lipid peroxidation and liver cell injury by iron chelation. Gut 1989; 30: 510 .

37. Yuan GJ, Ma JC, Gong ZJ, Sun XM, Zheng SH, Li X. Modulation of liver oxidant-antioxidant system by ischemic preconditioning during ischemia/reperfusion injury in rats. World J Gastroenterol 2005; 11: 1825-1828.

38. Minor T, Isselhard W, Yamamoto Y, Obara M, Saad S. The effects of allopurinol and SOD on lipid peroxidation and energy metabolism in the liver after ischemia in an aerobic/anaerobic persufflation. Surg Today 1993; 23: 728 .

39. Michiels C, Raes M, Toussaint O, Remacle J. Importance of Seglutathione peroxidase, catalase, and $\mathrm{Cu} / \mathrm{Zn}$-SOD for cell survival against oxidative stress. Free Radic Biol Med 1994; 17: 235-248.

40. Zhang XP, Xu HM, Jiang YY, Yu S, Cai Y, Lu B, Xie Q, Ju TF. Influence of dexamethasone on mesenteric lymph node of rats with severe acute pancreatitis. World J Gastroenterol 2008; 14: 3511-3517.

41. Kaçmaz A, User EY, Sehirli AO, Tilki M, Ozkan S, Sener G. Protective effect of melatonin against ischemia/reperfusion-induced oxidative remote organ injury in the rat. Surg Today 2005; 35: 744-750.

42. Ozturk H, Eken H, Ozturk H, Buyukbayram H. Effects of dexamethasone on small bowel and kidney oxidative stress and histological alterations in bile duct-ligated rats. Pediatr Surg Int 2006; 22: 709-718.

43. Oshima Y, Kuroda Y, Kunishige M, Matsumoto T, Mitsui T. Oxidative stress-associated mitochondrial dysfunction in corticosteroid-treated muscle cells. Muscle Nerve 2004; 30: 49-54.

44. Casey JP, Short BL, Rink RD. The effect of methylpre-dnisolone on hepatic oxygen supply and plasma lactate and glucose in endotoxemia. Circ Shock 1979; 6: 245-253.
45. Belghiti J, Noun R, Malafosse R, Jagot P, Sauvanet A, Pierangeli F, Marty J, Farges O. Continuous versus intermittent portal triad clamping for liver resection: a controlled study. Ann Surg 1999; 229: 369-375.

46. Usami M, Furuchi K, Shiroiwa H, Saitoh Y. Effect of repeated portal triad cross-clamping during partial hepatectomy on hepatic regeneration in normal and cirrhotic rats. J Surg Res 1994; 57: 541.

47. Helewski KJ, Kowalczyk-Ziomek GI, Konecki J. Neutrophils' contribution to ischaemia and reperfusion injury in liver. Wiad Lek 2007; 60: $47-52$.

48. Rudiger HA, Graf R, Clavien PA. Liver ischemia: apoptosis as a central mechanism of injury. J Invest Surg 2003; 16: 149-159.

49. Hatano E, Bradham CA, Stark A, Iimuro Y, Lemasters JJ, Brenner DA. The mitochondrial permeability transition augements Fas-induced apoptosis in mouse hepatocytes. J Biol Chem 2000; 275: 11814-11823.

50. Faubion WA, Gore GJ. Death receptors in liver biology and pathobiology. Hepatology 1999; 29: 1-4.

51. Ma M, Ma ZH. Effect of tumor necrosis factor-alpha in rats with hepatic ischemia-reperfusion injury. Hepatobiliary Pancreat Dis Int 2008; 7: 296-299.

52. Meldrum D.R. Tumor necrosis factor in the heart. Am J Physiol 1998; 274: 577-595.

53. Arras M, Höche A, Bohle R, Eckert P, Riedel W, Schaper J. Tumor necrosis factor in macrophages of heart, liver, kidney and in the pituitary gland. Cell Tissue Res 1996; 256: 39-49.

54. Pevni D, Frolkis I, Shapira I, Schwartz D, Schwartz I, Chernichovski T, Nesher N, Uretzky G. Cardioplegic ischemia or reperfusion: which is a main trigger for tumor necrosis factor production? Int J Cardiol 2008; 127: 186-191.

55. Yang YL, Li JP, Xu XP, Dou KF, Yue SQ, Li KZ. Protective effects of tumor necrosis factor alpha antibody and ulinastatin on liver ischemic reperfusion in rats. World J Gastroenterol 2004; 10: 3161-3164.

56. Kurcer Z, Oguz E, Ozbilge H, Baba F, Aksoy N, Celik H, Cakir H, Gezen MR. Melatonin protects from ischemia/reperfusion-induced renal injury in rats: this effect is not mediated by proinflammatory cytokines. J Pineal Res 2007; 43: 172-178.

57. Rodríguez-Reynoso S, Leal C, Portilla E, Olivares N, Muñiz J. Effect of exogenous melatonin on hepatic energetic status during ischemia/ reperfusion: possible role of tumor necrosis factor-alpha and nitric oxide. J Surg Res 2001; 100: 141-149.

58. Presman DM, Hoijman E, Ceballos NR, Galigniana MD, Pecci A. Melatonin inhibits glucocorticoid receptor nuclear translocation in mouse thymocytes. Endocrinology 2006; 147: 5452-5459.

Received March 23, 2015. Accepted May 28, 2915. 